WellBeing International

WBI Studies Repository

$5-2014$

\title{
Attitudes of Canadian Citizens Toward Farm Animal Welfare: A Qualitative Study
}

\author{
Jeffrey M. Spooner \\ University of British Columbia \\ Catherine A. Schuppli \\ University of British Columbia \\ David Fraser \\ University of British Columbia
}

Follow this and additional works at: https://www.wellbeingintlstudiesrepository.org/farawel

Part of the Agribusiness Commons, Animal Studies Commons, and the Business Law, Public Responsibility, and Ethics Commons

\section{Recommended Citation}

Spooner, J. M., Schuppli, C. A., \& Fraser, D. (2014). Attitudes of Canadian citizens toward farm animal welfare: A qualitative study. Livestock Science, 163, 150-158.

This material is brought to you for free and open access by WellBeing International. It has been accepted for inclusion by an authorized administrator of the WBI Studies Repository. For more information, please contact wbisr-info@wellbeingintl.org.

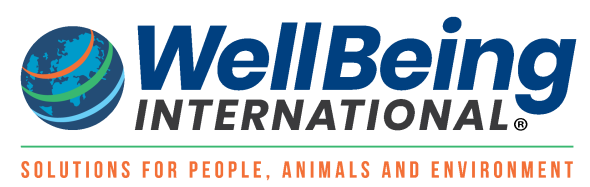




\title{
Attitudes of Canadian Citizens Toward Farm Animal Welfare: A Qualitative Study
}

\author{
Jeffrey M. Spooner, Catherine A. Schuppli, David Fraser
}

University of British Columbia

\author{
KEYWORDS \\ animal welfare, Canada, public, consumers, food, animals
}

\section{ABSTRACT}

As part of a larger project to determine if there are animal-welfare-related values shared by some commercial food-animal producers and non-producers in Canada, open-ended, semi-structured interviews were conducted to elicit opinions about animal welfare among 24 urban and rural residents not involved in commercial animal production. All participants possessed a self-described interest in food animal well-being and were therefore assumed to represent the views of Canadian non-producers most apt to engage in efforts to shape the animal welfare policies of governments and businesses. Participants described animal welfare in moral or ethical terms, expressed virtually unanimous support for animals having access to "natural" living conditions, and (somewhat less often) linked animal welfare to positive affective states. Maintaining reasonable health and biological functioning was seen as important but was not to take precedence over the benefits of natural living. Participants favoured small family farms and unanimously objected to confinement housing. Participants did, however, offer qualified support for intensive practices and were unanimous in not assigning blame to producers, whom they regarded sympathetically. Predictably perhaps, given our sample, most were critical of industries preoccupied with profits and of consumers who unthinkingly seek cheap food. Recommended ways of improving welfare included instilling in consumers a greater appreciation for the intrinsic value of humanely reared animals, and better education of children regarding the connection between animals and food. Disagreements arose over the welfare implications of organic production and approaches to animal advocacy. Differing demographic backgrounds, experiential involvement with food animals and knowledge of food animal production practices may have influenced the nature or specificity of welfare concerns. Many participants admitted a lack of knowledge about contemporary production practices and some expressed an interest in obtaining additional knowledge. These findings contribute to a broader effort to identify shared values among different stakeholder groups as a basis for formulating widely acceptable, farm animal care and handling polices.

\section{Introduction}

Farm animal welfare has often been an area of conflict between producers and non-producers. In the USA, citizen petitions have given rise to legislative initiatives - including California's high-profile, multi- 
million-dollar media battle over "Proposition 2" in 2008 - which have resulted in the prohibition of certain confinement housing systems in numerous states (Centner, 2010). In Europe, surveys revealing citizen concern over intensive agriculture and pressure for higher farm animal welfare standards (European Commission, 2005, 2007; Kjærnes and Lavik, 2008) have led to widespread regulations. As noted by Driessen (2012) "adversarial and entrenched oppositions" have tended to dominate public discussion of farm animal welfare.

Perhaps, however, conflict is not the only option. According to Friedman and Himmelstein (2006), p. 524, research on conflict resolution has shown that "deeper understanding by the parties of their own and each other's perspectives, priorities, and concerns enables them to work through their conflict together." Moreover, as noted by Picard and Melchin (2007), p. 40, "developing in sight about our values and interests can change how we experience conflict, which can shift the conflict situation from impasse to an attitude of openness to the concerns of the other party and to the possibility of resolution."

In this context, research intended to identify beliefs and concerns related to animal welfare, as held by both producers and non-producers, has been undertaken in Europe, principally in connection with the Welfare Quality Project (Blokhuis et al., 2010). In contrast, public understanding of farm animal welfare has received considerably less attention in other geographic areas. With relatively few European studies available at the outset of our project, and given the considerable geographic and cultural differences between Canada and Europe, we undertook a multi-study project intended to elicit some citizen views regarding good or satisfactory lives for food animals. Specifically, our intent was (i) to discern whether there are animal-welfare-related values shared by some commercial food-animal producers and nonproducers in Canada, and (ii) if so, how those shared values might form or contribute to policies that could be supported by both groups. More broadly, our purpose has been to facilitate discussion, identify shared values regarding animal welfare, engender self-awareness among stakeholders, and facilitate consensus-building on farm animal care and handling practices. It is hoped that shared values, reflecting the broadest consensus possible (e.g., Tuyttens et al., 2010), maybe identified and used to contribute to policies that could be widely supported. In this study, research was conducted to ascertain the views of some Canadian non-producers interested in farm animal well-being.

\section{Methods}

Interviews were conducted with 24 members of the Canadian public residing in British Columbia (12), Alberta (2), Manitoba (1), Ontario (6), Quebec (1) and Nova Scotia (2). Participants were recruited through a purposive sampling strategy which sought: (i) adults with an a priori interest in farm animal welfare, and (ii) a rural-urban residency ratio consistent with Canadian demographics (Statistics Canada, 2006). Those with an existing interest were expected (i) to be willing and able to discuss farm animal welfare over the course of an anticipated 90-min interview, (ii) to be potentially/relatively informed about modern production practices, and (iii) to represent citizens most inclined to advocate for animal welfare to governments and businesses. Previous research has shown that women are more concerned about the treatment of animals (Ellis et al., 2009; Herzog, 2007; Herzog et al., 1991; Pifer et al., 1994; Taylor and Signal, 2005), and that women comprise the majority of those engaged in animal rights movements (Herzog, 1993). Hence, it was expected (and accepted) that we would elicit a disproportionate number of female participants.

According to Kendall et al. (2006), p. 418, who found that "talking with farmers" was significantly related to attitudes about farm animal care, efforts were also made to stratify the sample on the basis of urban and rural residency (i.e., to interview some citizens living in rural areas who were presumed to have more exposure to farm animals and animal producers). This was also consistent with Vanhonacker et al. (2008) and Prickett et al. (2010). To this end, and among other recruitment methods, advertisements were 
posted in rural libraries and various regional publications. In addition, participants were recruited directly by the researchers, members of the UBC Faculty of Land and Food Systems, through advertisements on the UBC Animal Welfare Program website, and with the assistance of some participants themselves. Participants were deliberately sought with an a priori interest in farm animal welfare and not those opposed to all use of animals by people. Ultimately, only one such person applied to participate but withdrew voluntarily before being interviewed.

\subsection{Participant information}

The 24 participants included 21 females and 3 males. Fifteen (62.5\%) described themselves as from urban environments and nine (37.5\%) from rural. Participants had had different degrees of exposure or experience with farming. Five had been raised on hobby or commercial farms, five had family connections to a farm which they visited, four had worked on farms as students, volunteers or employees, six had visited friends' farms with some frequency, and four had rarely visited farms. Two of the 24 were currently hobby farmers. Participants also had varying degrees of involvement with animal protection organizations. One was employed by an animal protection organization, 17 had volunteered with or supported such an organization in some way and the remaining 6 had not. Six participants described themselves as "practicing vegetarians" (i.e., no consumption of food animal flesh). Among the remainder, five described their diets as being somewhat meat-restricted (usually no red meat) for philosophical reasons while two reported limiting their red meat intake owing to concern over cholesterol levels. Compared to typical demographics, our sample was over-represented by supporters of animal protection organizations and by those with familial or other forms of experience with farm animals/operations.

\subsection{Interviews}

Semi-structured interviews, which lasted approximately $90 \mathrm{~min}$, were conducted face-to-face (22) or by telephone (2). Face-to-face interviews were preferred in the interests of establishing rapport. Individual interviews were preferred in order to help capture both specific and broader views about welfare in a given context. Moreover, face-to- face focus groups were not possible owing to the geographic distances between participants. Seventeen interviews were conducted by two interviewers with one leading and a second contributing supplemental probes and follow-up questions. All interviews were tape-recorded and transcribed (verbatim). Notes were also taken during the original interviews and reviewed in detail afterwards by one or both interviewers for evidence of emergent, preliminary themes. Immediately before each interview, participants were given a verbal summary of the study and were asked to review and sign a consent form, approved by the University of British Columbia Research Ethics Board, stressing confidentiality and the right to withdraw from the study at their discretion, although none withdrew.

Initial questions covered demographic details, experience of farms, involvement with animal protection organizations and current diet. All subsequent questions sought perspectives on farm animal welfare in varying ways. Participants were invited to respond to an open-ended, semi-structured schedule of questions that had been pilot-tested on student volunteers involved in farm animal welfare and production. Respondents were encouraged to relate: (i) what "farm animal welfare" meant to them; (ii) criteria they might use to assess whether animals were being subjected to positive or negative welfare practices on farms; (iii) whether they had always held their current views on animal welfare as well as any notable influences on their thinking; (iv) their opinions about viewpoints that differed from their own; (v) the extent to which animal welfare influenced their behavior as consumers plus their preferences, if any, regarding animal-welfare-related product labeling; (vi) the role that key stakeholders (including consumers, producers, governments, production and retail industries, advocates, media, veterinarians and others) can or should play in facilitating animal welfare; and (vii) their vision of an ideal animal-related society and what a first step in that direction might require. 
Some participants were also invited to respond to one of two additional textual queries. Three participants were presented with a brief "questerview" (a research tool in which a self-completed questionnaire is administered within a qualitative interview; see Adamson et al., 2004) intended to further elucidate views on farm animal welfare. While theoretically inviting, this elicitation method was eventually deemed to be ineffective by the researchers and was abandoned. Subsequently, fifteen others received a compilation of 30 welfare-related attributes reflecting three elements of animal welfare (basic health and functioning, natural living, and affective states, as described by Fraser et al. (1997)). Both the questerview and attributes lists were offered to participants in order to help flesh out responses mainly in cases where initial comments about animal welfare were brief or general. Participants were invited to address any of the 30 attributes in light of their earlier comments about animal welfare.

Respondents answered most or all questions which were usually posed in the same order. In some cases, participants were accompanied by life partners who contributed comments that were transcribed and treated as participants' views. Participants were also invited to volunteer any additional comments relevant to animal welfare, and all were encouraged to contact the researchers to add any supplementary comments afterwards if desired. One supplemental comment was received. In turn, participants were normally asked for permission by the researchers to initiate follow-up contacts, and all agreed. Participants were invited to receive copies of any reports arising from their interview(s) and all accepted.

Transcriptions were reviewed many times in conjunction with preliminary memos and field notes. Analysis was conducted using a "constant comparison" method (e.g., Glaser and Strauss, 1967); specifically, participant comments were individually segmented, identified and classified or "coded" - until no further codes were required to reflect new data - before being compared and grouped with similar or related comments from other participants. This process continued until emergent patterns appeared within the data that were subsequently identified as themes and outlined below. Analysis was assisted by the use of NVivo software. Numbers were arbitrarily assigned to each participant for identification purposes and these appear with each quotation. Verbatim responses appear in quotation marks.

\section{Results}

\subsection{Linking animal welfare to moral concepts}

When asked to describe what the term "farm animal welfare" conveyed to them, most participants made reference to morals or ethics and the humane rearing of animals over the course of their entire lives:

250: The ethical treatment of the animals while they're being raised from the farm to the slaughterhouse that they're treated humanely, and that they're farmed in a sustainable manner.

Some participants also used terms related to oppresssion ("enslaved", "colonialism", "concentration camps") when referring to animal production practices.

\subsection{Elements of animal welfare}

\subsubsection{Natural environments}

Participants overwhelmingly related animal welfare to access to natural environments and the ability to express natural behavior. Frequent references were made to animals "just being outside", "having their feet on turf, not just concrete", "grazing out" and "being able to get outside and breathe fresh air and feel daylight". Most regarded natural living as being consistent with animals' natural predispositions. Examples included references to animals living in habitats that "resemble the habitats that they would be in", "according to its instincts or how it would normally spend its time", "promoting species-specific behaviors 
... mimicking their evolutionary wild state", and having "natural food or sources of natural light". Participants also emphasized the importance of "choice" associated with natural living and "not to restrict the normal ... movement process of an animal":

216: They can choose what they eat, where they eat. They can lie down if they want to. They can go where they want to.

103: They have a choice to able to ... go indoors or outdoors, or a choice of whether they ... are able to play, or things like that.

Participants emphasized natural social behavior with phrases including "it's their natural instinct to want to socialize in groups", "to have others of their kinds around", "contact between mothers and young" and to "display their normal, behavioral traits." One participant linked natural behavior to health, claiming that animals in feed lots are:

250: ... not exercising. They're not healthy. They're more prone to getting diseases. So I guess I envision ... cattle grazing on lots of land, and space, and having room to roam.

Some views appeared to reflect personal preferences projected onto animals:

204: The ... free-range thing I think is important .... I'm a dancer and I'm happiest in an empty studio. So that, to me, speaks of abundance and lots of space.

202: Intuitively I know that if I was kept in a confinement stall ... for long, long periods of time, it has got to involve suffering.

240: I know that I would hate to be in a cage, so I can extrapolate that a chicken would hate to be in a cage.

\subsubsection{Affective states}

Participants often cited affective states when defining animal welfare, stressing the importance of animals remaining free from "pain and fear", "stress", "suffering" and "loneliness". Many also made allusions to animals experiencing positive welfare or "happiness". Freedom from pain was further emphasized amidst concerns about the infliction of pain on animals without appropriate pain management. For one participant, pain minimization was considered "an absolute priority":

218: In an ideal world ... every procedure that's done, if it's necessary such as dehorning, is done in such a way in which the animal is respected as far as their pain management needs are concerned.

\subsubsection{Health}

Participants made relatively few references to health and statements that were made were often qualified. In particular, although participants related animal health to animal welfare, they did not support efforts to protect animal health at the expense of access to natural environments:

122: Overall in my opinion the benefits of the more natural life outweigh any potential disadvantages of the occasional injury. ... There's got to be a limit to optimizing biological health at the expense of what you're losing in the natural life of an animal.

106: So it's not just biological - are they getting enough food, and are they surviving ... not getting sick and whatnot. But it's also are they emotionally and socially satisfied? 
Instead, participants favoured a somewhat moderate approach to biological health and functioning that reflected a combination of reasonable preventative measures and prompt attention to injuries or illnesses. One advocated a herd size "that's manageable from the point of view of regular contact with each individual animal to see if they are injured, but at the same time allowing them out in a more natural environment." When asked about protecting animals from injuries to maintain health or to avoid pain and suffering, one participant seemed to assign greater priority to the animal's affective state:

122: Health is important to the animal but the animals themselves suffer and feel pain. That's more important to me.

Another wanted animals to be raised under optimal conditions so that not only are they producing healthy, safe meat, they're also living their lives "in a way that they enjoy." Still another wanted animals to be comfortable and commented that while it would be "nice for them not to have diseases" was "suspicious" about excessive or inappropriate use of "vaccinations and ... hormones."

\subsection{Proper handling as reciprocal recognition}

Participants often associated good or satisfactory lives for animals with careful handling by producers or caretakers. Among other priorities, participants stressed the need for "a level of respect", "a personal relationship", and an awareness "of how animals react." Animal welfare for most participants entailed providing farm animals with a reasonable degree of reciprocal consideration for the sacrifices demanded of them. For example:

202: [To have a] ... system where in we're going to eat animals and we're going to use them to create dairy products or such. But we're going to do it in the knowledge that these are creatures, they're sentient beings, they have a capacity to suffer and to feel pain, to experience emotional distress.

\subsection{Animal welfare in relation to type of production}

Participants clearly believed that good or satisfactory lives for farm animals were most apt to be attained through small family farming:

240: I think especially small farmers who interact with their animals in a more natural circumstance probably care a great deal about their animals.

250: Well, I guess just looking back to the smaller farms, and how it used to be - communication, petting the animal, going out there and just giving them nurturing and loving.

Participants widely - and often strongly - opposed intensive animal production which was regarded as denying animals access to natural environments and/or opportunities to express natural behaviors in favor of increased production:

200: I've seen chickens that are put in where there's ... not a window, or a natural light going into the building ... it's ... not a pleasant thing.

174: Very large intense operations where the hogs are kept inside all day - that, to me, is not consistent with animal welfare.

202: Milk-fed veal is a big issue in terms of raising an animal to produce a particular type of food and in doing so, causing it to suffer. 
While participants clearly favoured small-scale production, some did allude to animal welfare benefits from modern technological or intensive production methods:

106: Maybe a lot of animals don't need to be free-range to have a good life ... They could live very well within a barn if it's set up right ... Some wouldn't agree with me on that. They'd say, "No, they all have to be free range." But physically you couldn't do that.

204: I think that the technology makes things worse for them. But, on the other hand, maybe the technology, if used in a different way ... could ease the suffering. Maybe ... [it could] ... ensure that their surroundings are clean and ... that they're properly fed, and ... at the right temperature.

One participant also maintained that knowledgeable people could design indoor systems which benefited animals, while another lauded the merits of a childhood relative's indoor cage-free system for hens which could also have been engineered to provide outdoor access while ensuring protection from predators.

Despite their opposition to large-scale production, no participants directly criticized individual producers or mid-level managers employed in large production companies. Participants were not unsympathetic to the economic realities of contemporary farm animal production and did not want to hamper individual producers or their families as this would amount to "punishing the wrong people":

204: Maybe the first step has to do with legislation that [is] ... not just saying farmers: "You have to ... pull up your socks and ... adopt ethical farming practices" because then that's laying the blame at their feet. And they are ... probably making a lot of these choices because they feel that they have to.

103: I think farmers are really aware on animal welfare ... and I think that ... often times the animal welfare standards may fall short because they're not making enough money. ... The economy doesn't allow them to do repairs on buildings and things like that.

Participants also appreciated that economic concerns could impede producer efforts to improve animal welfare, and some looked upon individual producers as having little power to create industry-wide changes:

200: They are a business. So you have to make sure that they can remain competitive. You can't just regulate our farmers, and put restrictions on them, and still let everyone import ... with no regard to animal welfare.

Nonetheless, many participants were critical of what they regarded as an excessive focus on profit which, they maintained, had contributed to intensive animal production. For example, participants saw profit and greed as detrimental to animal interests, humanity and kindness. According to one, "when the focus is only the bottom line, things just go the wrong way."

Participants did acknowledge, however, the challenges for even well-intentioned operators of maintaining high animal welfare standards with in large, profit-oriented units. According to one participant, in discussing the appeal of idyllic, small farm environments on one hand, and market-based realities on another, "I don't know how you reconcile those." There was also awareness that consumers, seeking lower-priced food, supported intensive production. According to one participant, "intensive agricultural production makes food cheaper and I would say the majority of people - of consumers - think about the cost." Another participant, despite strongly favouring outdoor pig production, stressed that outdoor rearing could result in pork being too expensive for less affluent people. Many also felt that consumers could influence improvements in farm animal welfare if willing, noting that consumers "vote every time they spend money". 


\subsection{Differing views among study participants}

Explicit differences among participants emerged on several topics. Some participants equated organic production with more acceptable animal welfare:

240: It is my understanding that organic farmers, whether or not they're certified, tend to allow animals to engage in more natural behaviors. And I think that's a huge difference.

186: I eat organic meat almost exclusively, and I do this because I have decided that those animals are going to be treated better.

Others, however, saw organic production as unrelated to, or not in the interests of, animal welfare:

208: I don't buy organic milk. I don't buy organic cheese. Because again, to me, there is no assurance that farm animal welfare is being considered in the process as well.

138: And then there's a lot of times when organic is simply not the best thing for animal welfare. [Failing to provide] antibiotics is a really good example of that.

Participants also differed over the role of animal advocacy organizations in farm animal welfare. Some expressed largely unqualified support for the work of advocates; others expressed support for advocacy groups, but were concerned about unfactual claims made in advocacy campaigns; Others - notably participants who had been raised on family farms - were openly critical of high-profile advocacy groups like "PETA".

\subsection{Slaughter, transportation and auction markets}

Participants frequently and spontaneously expressed specific welfare concerns over animal slaughter. According to one participant, for example:

122: I've been to a slaughterhouse ... and I'll never forget it. ... It was stressful for the workers. It was stressful for the students. It was stressful for the animals. There was so much noise. It was just an assembly line and the animals were tripping and it was pretty horrific.

Specific concerns were raised over improper or ineffective stunning:

252: I think there are some standards that are supposed to be in place where the animals are stunned or rendered unconscious before the actual slaughter occurs. But that doesn't always successfully take place and so some animals are slaughtered ... [when] ... they're conscious.

One participant was concerned about ritual slaughter "because the animal's not stunned before they're slaughtered".

To reduce long distance transportation to slaughter plants, participants were strongly in favor of more local slaughter plants or the use of mobile abattoirs capable of traveling to the animals:

107: From what I've read and heard, animals being transported to slaughter generally are transported incredibly long distances these days. ... Methods of getting them there and the length of time it takes ... really disturb me.

Two participants, (one currently a hobby farmer and another raised on a farm) voiced explicit concerns about auction markets where animals are bought and sold: 
218: Well, I happened to be at the cattle market recently ... [to see if] ... anything has changed. Are the animals in better shape? Is anyone doing anything about these poor, emaciated cows? And basically nothing has changed. The animals are regularly beaten and prodded and pushed around...

\subsection{Diminished value of food animal products}

Participants strongly maintained that a factor contributing to poor animal welfare is the disconnection in the minds of consumers between animal products and the animals that produce them. In turn, this resulted in a lack of connection to the treatment of the animals themselves:

210: "Factory-produced" meat and eggs are ... available in such vast quantities that people just buy them without thinking about where they've come from - or people kind of disassociate the meat from the animal.

107: I think that part of the responsibility of being a meat-eater is making that connection that an animal died in order for you to eat what's on your plate ... to make that connection that here was a living, breathing creature.

Furthermore, many believed that consumers no longer value food animal products as they once did, nor pay sufficient prices:

105: We think that we're somehow entitled to cheap, cheap food. And I don't think that's the case.

107: I don't think we're paying enough, which is probably the problem.

138: I don't think the consumers are ever asked to take on too great a price. ... All food should be more expensive - way more expensive.

Some also maintained that higher consumer prices would facilitate higher animal welfare:

186: We should be paying way, way, way more money to eat this stuff. ... It's too cheap - that's the problem.

\subsection{Promoting welfare}

Participants advocated two approaches to encourage support for welfare-friendly food. The first involved efforts to enlighten consumers about the value of such products. According to one participant, given that consumers are more apt to pay premium prices for products that are perceived to be of higher intrinsic value, consumers would be more inclined to value the quality of a food-animal product coming from an animal that had "had a better life." The second approach was to educate children - especially urban children - about the origins of their food through more direct exposure to small family farms, farmers and farm animals:

180: I think you have to start with ... educating the children that are coming up in school, about farm animals and that the animals are raised for a purpose.

202: I would say that kids should understand ... that a pig isn't just a piece of bacon - that it is actually a creature that likes to run and play and have a lot of fun. ... So I think kids should be introduced at a very young age to being around animals." 


\subsection{Knowledge deficits}

Participants occasionally acknowledged that they lacked first-hand knowledge about intensive rearing methods. One participant, for example, "heard how they're kept in cages that are so small that they can't even turn around", but also noted "not that I'm an expert in this." Furthermore, some expressed willingness to acquire more factual information before drawing conclusions, even if that meant overturning longstanding assumptions. For example, one participant emphasized "I need to have a more balanced view."

\section{Discussion}

This study was part of a larger project intended to determine whether there are animal-welfare-related values shared by some commercial food-animal producers and non-producers in Canada. For this study we opted to use in-depth discussions because "a qualitative approach is especially appropriate when little is known about a topic" (Knight and Barnett, 2008, p.32), and we used a purposive sampling method to select citizens with an existing interest in farm animal welfare in order to achieve comments of sufficient depth for meaningful analysis. A similar recruitment method was also used in one of the first multi-country studies of European consumer views regarding animal welfare (Harper and Henson, 2001). The ensuing high proportion of female participants was similar to that used by Kohler (1999). The approach also serves to capture the views of a sub-set of citizens most likely to engage in efforts to shape the animal welfare policies of governments and other parties.

Unlike Canadian beef (Spooner et al., 2012) and pig producers (Spooner et al., 2013), participants in this study were comfortable using the term "farm animal welfare", often with reference to ethical norms and values (not an unexpected result given our selection criteria). Virtually all participants in this study equated good or satisfactory lives for food animals with access to natural environments and the ability to express natural behavior. In general, participants supported raising animals outdoors with the freedom to behave as they desired. More specifically, they emphasized opportunities for animals to engage in natural activities such as maternal-offspring interactions. When speaking of "natural" environments, participants appeared to focus on positive elements rather than negative features such as the harsh weather and predation that tend to be emphasized by producers (e.g., Spooner et al., 2013).

Animal welfare scientists often note the advantages of using animal-based criteria of animal welfare (good health, performance of types of behavior) rather than resource-based criteria such as provision of specific environmental features (e.g., Webster, 2009). Participants in this study cited some animal-based criteria such as good health and freedom from pain, but they generally focused on resources, notably access to open, unenclosed areas, while clearly believing that these environments would lead necessarily to healthy, happy animals. In contrast, many producers emphasize animal-based criteria, and express skepticism over the welfare benefits of seemingly natural environments (Lassen et al., 2006; Spooner et al., 2012).

Participants appeared to consider animals to have intrinsic value beyond their utilitarian value to humans. In this context, many emphasized reciprocity, stressing the need for mutually beneficial relationships between producers and animals. Participants also cited a moral need to provide animals with good lives in exchange for the sacrifice demanded of them. In short, farm animals were to be recognized as sentient beings deserving of respect and appreciation beyond provision of basic care and comfort.

Notably, no participants maintained that producers were to be held responsible for subjecting animals to the shortcomings of intensive production. On the contrary, participants - perhaps assuming that farmers naturally wanted to rear animals extensively, perhaps on small family farms - appeared to believe that 
producers had likely adopted confinement production owing to market or other economic demands over which they had little control. Moreover, while participants wished for less intensive production, none wanted to see farmers or their families suffer as a result.

Participants also stressed the relationship between economics and animal well-being. Most blamed poor food animal welfare on a society-wide preoccupation with profit and greed. Participants were widely critical of consumers and their quest for "cheaper food". While distinct from other findings in which consumers have assigned the responsibility for animal welfare to other stakeholders including farmers and veterinarians (e.g., Meehan et al., 2002), this finding is likely a direct reflection of our sample. Still, participants were frustrated that consumers failed to comprehend or to operationalize the power that they possessed to bring about improved animal welfare through deliberate purchasing. Such assertions may represent "distancing" (Serpell, 1996) in which stakeholders - usually producers (according to te Velde et al., 2002) - attempt to cope with feelings of discomfort or guilt about contemporary care practices by shifting responsibility for enhanced welfare to others. For example, according to Harper and Henson (2001), consumers revealed a perceived lack of power to affect welfare standards. In addition, according to some participants, food prices had been driven down to the point that animal welfare was affected. If true, then producers may require some form of protection from market pressures that force them to cut back on welfare-related practices (Fraser, 2008).

Numerous studies - principally in Europe - have explored non-producer views about farm animal welfare in the past decade. Despite notable cultural differences between Canada and Europe, our findings agreed with European results in many respects, notably: (i) strong preferences for natural environments (Boogaard et al., 2008; Ellis et al.,2009; Krystallis et al., 2009; Lassen et al., 2006; Maria, 2006; Miele and Evans, 2005; te Velde et al., 2002; Vanhonacker et al., 2008); (ii) objections to animal suffering and/or pain associated with modern production methods (Boogaard et al., 2011b; Miele and Evans, 2005; Miele et al., 2011; Phillips et al., 2009; Tuyttens et al., 2010; Vanhonacker et al.,2008); (iii) opposition to a singular focus on animal health at the expense of natural living (Evans and Miele, 2007; Frewer et al.,2005; Lassen et al., 2006; Veissier et al., 2011); (iv) support for humane handling (Boogaard et al., 2008; Boogaard et al., 2011b; Ellis et al., 2009; Miele and Evans, 2005; Vanhonacker et al.,2008); (v) preferences for small family farms (Krystallis et al.,2009; Lassen et al.,2006; Miele and Evans, 2005); (vi) strong opposition to confinement production (Boogaard et al., 2011b; Lassen et al., 2006; Miele and Evans, 2005; Miele et al., 2011); (vii) qualified support for some aspects of contemporary production (Boogaard et al., 2008; Boogaard et al., 2011a, 2011b; Harper and Henson, 2001); (viii) empathy for intensive producers (Boogaard et al., 2011b; Lassen et al., 2006; te Velde et al., 2002; Vanhonacker et al., 2010); (ix) mixed opinions regarding organics and animal welfare (Boogaard et al., 2011b; Lund, 2006; Verhoog et al., 2007;); and (x) concerns related to slaughter and animal transport (Miele and Evans, 2005). Thus, despite our purposive selection of participants, our major findings regarding citizen views clearly reflect those of more demographically balanced qualitative (i.e., Evans and Miele, 2007; Lassen et al., 2006; te Velde et al., 2002) and quantitative studies (e.g., Vanhonacker et al., 2008).

Our results showed no discernible division of views between urban and rural residents. Similarly, Kendall et al. (2006) noted that current residence variables were unrelated to attitudes about animal welfare. However, family and/or personal experience of farm animals - which varied considerably among participants - appeared to correlate with differing welfare priorities and concerns. First, those most opposed to animal advocacy were found among former farm children, in keeping with previous findings (e.g., Boogaard et al., 2006; Kendall et al., 2006; te Velde et al., 2002). Second, those with less familyrelated farm experiences appeared most opposed to confinement production based on philosophical principles. Third, those with a history of director frequent involvement with farm animals in their youth were usually more targeted in their concerns. Notably, those with first-hand knowledge of auction markets 
expressed major concerns about the practice (as did some beef producers in Spooner et al., 2012), whereas most other participants were likely unfamiliar with conditions at these sales. Similarly, some participants expressed intense opposition to pain associated with invasive management practices; the lack of comment from others may have reflected lack of awareness. Indeed, public awareness of piglet castration, for example, has been found to be quite limited (e.g., Heid and Hamm, 2012; Tuyttens et al., 2011; Vanhonacker and Verbeke, 2011; Vanhonacker et al., 2009). In contrast to several European studies (e.g., Boogaard et al., 2011a, 2011b; Ellis et al., 2009; Hall and Sandilands, 2007; Miele and Evans, 2005; Miele et al., 2011; Vanhonacker et al., 2010), participants did not raise concerns about animals receiving natural, healthy, or organic feed. The difference may be due to recent European experiences of animal disease outbreaks attributed to contaminated feed as reflected by Ellis et al.(2009) and Miele and Evans (2005).

Participants attributed reduced welfare standards to people failing to link animal products with the animals that produce them. In response, participants widely maintained that efforts were needed to reestablish this awareness and to facilitate a more realistic understanding among children about food products, animals and animal production. According to Harper and Henson (2001), however, efforts to educate consumers are apt to encounter a barrier of "voluntary ignorance" or, according to te Velde et al. (2002), "functional ignorance". As explained by Miele and Evans (2005) "it would seem that a significant subsection of consumers simply did not want to know about the animal welfare conditions of the foods they were consuming." As noted by Jolly et al. (2004) many participants also saw a need to establish an awareness of food animals among children through direct exposure to animals, preferably in conjunction with formal education.

\section{Conclusion}

Participants in this study appeared to reflect what might be called a realistically informed idealism. Such an orientation is apt to benefit all stakeholders in future negotiations over policy and practices for animal care and handling. As one example, participants supported access to natural living conditions for animals while acknowledging that geographic and economic factors are likely to limit the amount and conditions of outdoor access that can feasibly be provided. In addition and despite preferences to the contrary, a few participants acknowledged that producers need to use economies of scale in competitive markets.

Given that Canada has not witnessed the same degree of high-profile, public opposition to intensive food-animal rearing practices as in Europe or the USA (e.g., Centner, 2010), there may be more scope for dialog between producers and non-producers on existing (and perhaps shared) values and attitudes about animal welfare. For example, and as with previous findings, some participants expressed a lack of knowledge about contemporary production methods (Ellis et al., 2009; Frewer et al., 2005; Lassen et al., 2006; te Velde et al., 2002; Vanhonacker et al., 2008), and some expressed a willingness to acquire more reliable or accurate information. Such open-mindedness may indicate a willingness to engage with those actively involved in animal production as a basis for mutual understanding and development of broadly accepted policy.

\section{Conflict of interest statement}

None declared.

\section{Acknowledgments}

Funding for this study was provided by the Social Sciences and Humanities Research Council of Canada (SSHRC) and the UBC Animal Welfare Program and its donors. Valuable support was provided by Drs. Unni Kjaernes, Harry Blokhuis, Bailey Norwood, Bettina Bok and Birgit Boogaard. We also thank our 
anonymous reviewers for your valuable comments. A special thanks to all participants who cannot be named for reasons of confidentiality but whose openness and warm hospitality made the study an enjoyable as well as an informative experience.

\section{References}

Adamson, J., Gooberman-Hill, R., Woolhead, G., Donovan, J., 2004. 'Questerviews': using questionnaires in qualitative interviews as a method of integrating qualitative and quantitative health services research. J. Health Serv. Res. Policy 9, 139-145.

Blokhuis, H.J., Veissier, I., Miele, M., Jones, B., 2010. The Welfare Qualitys project and beyond: safeguarding farm animal well-being. Acta Agric. Scand. A Anim. Sci. 60, 129-140.

Boogaard, B.K., Bock, B.B., Oosting, S.J., Wiskerke, J.S.C., van der Zijpp, A.J., 2011a. Social acceptance of dairy farming: the ambivalence between the two faces of modernity. J Agric. Environ. Ethics 24, 259-282.

Boogaard, B.K., Boekhorst, L.J.S., Oosting, S.J., Sorensen, J.T., 2011b. Socio-cultural sustainability of pig production: citizen perceptions in the Netherlands and Denmark. Livest. Sci. 140, 189-200.

Boogaard, B.K., Oosting, S.J., Bock, B.B., 2006. Importance of emotional experiences for societal perception of farm animal welfare: a quantitative study in the Netherlands. In: Kaiser, M., Lien, M.E.(Eds.), Ethics and the Politics of Food, Wageningen Academic Publishers, Wageningen, Netherlands, pp.512517.

Boogaard, B.K., Oosting, S.J., Bock, B.B., 2008. Defining sustainability as a socio-cultural concept: citizen panels visiting dairy farms in the Netherlands. Livest. Sci. 117, 24-33.

Centner, T.J., 2010. Limitations on the confinement of food animals in the United States. J. Agric. Environ. Ethics 23, 469-486.

Driessen, C., 2012. Farmers engaged in deliberative practices: an ethnographic exploration of the mosaic of concerns in livestock agriculture. J. Agric. Environ. Ethics 25, 163-179.

Ellis, K.A., Billington, K., McNeil, B., McKeegan, D.E.F., 2009. Consumer perceptions of dairy welfare and production: a role for vets in public education? Cattle Pract. 17, 148-152.

European Commission, 2005. Attitudes of consumers towards the welfare of Farmed Animals, Special Eurobarometer 229. Available from: 〈http://ec.europa.eu/food/animal/welfare/euro_barometer25_en.pdf〉 (accessed 17.04.13.).

European Commission, 2007. Attitudes of EU Citizens towards Animal Welfare, Special Eurobarometer 270. Available at: 〈http://ec.europa.eu/public_opinion/archives/ebs/ebs_270_en.pdf) (accessed 17.04.13.).

Evans, A., Miele, M., 2007. Consumers' Views about Farm Animal Welfare: Part I. Welfare Quality Report Number 4. Cardiff University Press, Cardiff, UK.

Fraser, D., 2008. Animal welfare and the intensification of animal production. In: Thompson, P.B. (Ed.), The Ethics of Intensification, Springer Verlag, Heidelberg, pp.167-189. 
Fraser, D., Weary, D.M., Pajor, E.A., Milligan, B.N., 1997. A scientific conception of animal welfare that reflects ethical concerns. Anim. Welf. 6, 187-205.

Frewer, L.J., Kole, A., Van De Kroon, S.M.A., de Lauwere, C., 2005. Consumer attitudes towards the development of animal-friendly husbandry systems. J. Agric. Environ. Ethics 18, 345-367.

Friedman, G., Himmelstein, J., 2006. Resolving conflict together: the understanding-based model of mediation. J. Disput. Resolut. 2006, 523-553.

Glaser, B.G., Strauss, A.L., 1967. The Discovery of Grounded Theory: Strategies for Qualitative Research. Aldine Publishing, Chicago.

Hall, C., Sandilands, V., 2007. Public attitudes to the welfare of broiler chickens. Anim. Welf. 16, 499512.

Harper, G., Henson, S., 2001. Consumer concerns about animal welfare and the impact on food choice, EU Fair CT98-3678. Final Report Centre for Food Economics Research, University of Reading, Reading.

Heid, A., Hamm, U., 2012. Consumer attitudes towards alternatives to piglet castration without pain relief inorganic farming: qualitative results from Germany. J. Agric. Environ. Ethics 25, 687-706.

Herzog, H., 1993. The movement is my life: the psychology of animal rights activism. J. Soc. Issues 49 (1), 103-119.

Herzog, H., 2007. Gender differences in human-animal interactions: a review. Anthrozoos 20, 7-21.

Herzog, H., Betchart, N., Pittman, R., 1991. Gender, sex role orientation, and attitudes toward animals. Anthrozoos 4, 184-191.

Jolly, L., Krogh E., Nergaard, T., Parow K., Verstad B., 2004. The farm as a pedagogical resource: back ground for an devaluation of the co-operation between agriculture and primary school in the county of Nord-Trondelag, Norway. In: Proceedings of the Sixth European IFSA Symposium: Farmingand Rural Systems - Research and Extension, vol II. Sevicos de Reportografia da UTAD, Vila Real, Portugal. pp. 497-507.

Kendall, H.A., Lobao, L.M., Sharp, J.S., 2006. Public concern with animal well-being: place, social structural location, and individual experience. Rural Sociol. 71, 399-428.

Kjærnes, U., Lavik, R., 2008. Opinions on animal welfare and food consumption in seven European countries. In: Kjærnes, U., Bock, B. B., Roe, E., Roex, J. (Eds.), Consumption, Distribution and Production of Farm Animal Welfare. Welfare Quality® Reports No. 7., Cardiff University Press, Cardiff, pp. 1-126.

Knight, S., Barnett, L., 2008. Justifying attitudes toward animal use: a qualitative study of people's views and beliefs. Anthrozoos 21, 31-42.

Kohler, F., 1999. Consumer Concerns about Animal Welfare and the Impact on Food Choice: German Focus Group Report. University of Kiel, Germany.

Krystallis, A., de Barcellos, M.D., Kuegler, J.O., Verbeke, W., Grunert, K.G., 2009. Attitudes of European citizens towards pig production systems. Livest. Sci. 126, 46-56. 
Lassen, J., Sandoe, P., Forkman, B., 2006. Happy pigs are dirty! Conflicting perspectives on animal welfare. Livest. Sci. 103, 221-230.

Lund, V., 2006. Natural living - a precondition for animal welfare in organic farming. Livest. Sci. 100, 7183.

Maria, G.A., 2006. Public perception of farm animal welfare in Spain. Livest. Sci. 103, 250-256.

Meehan, H., Cowan, C., McIntrye, B., 2002. Food Choice and Consumer Concerns about Animal Welfare in Ireland. Final Report EC-FAIR Consumer Concern about Animal Welfare and the Impact on Food Choice (CT98-3678). Dublin, Ireland.

Miele, M., Evans, A., 2005. European consumers views about farm animal welfare. In: Butterworth, A., (Ed.), Science and Society Improving Animal Welfare. Welfare quality Conference Proceedings, 17/18 November 2005. Brussels, Belgium. pp. 13-29.

Miele, M., Veissier, I., Evans, A., Botreau, R., 2011. Animal welfare: establishing a dialogue between science and society. Anim. Welf. 20, 103-117.

Phillips, C.J.C., Wojciechowska, J., Meng, J., Cross, N., 2009. Perceptions of the importance of different welfare issues in livestock production. Animal 3, 1152-1166.

Picard, C.A., Melchin, K.R., 2007. Insight mediation: a learning-centered mediation model. Negot. J. 23, $35-53$.

Pifer, L., Shimizu, K., Pifer, R., 1994. Public attitudes toward animal research - some international comparisons. Soc. Anim. 2, 95-113.

Prickett, R.W., Norwood, F.B., Lusk, J.L., 2010. Consumer preferences for farm animal welfare: results from a telephone survey of US households. Anim. Welf. 19, 335-347.

Serpell, J., 1996. In the Company of Animals, Second rev. ed. Cambridge University Press (Canto), Cambridge.

Spooner, J., Schuppli, C.A., Fraser, D., 2012. Attitudes of Canadian beef producers toward animal welfare. Anim. Welf. 21, 273-283.

Spooner, J., Schuppli, C.A., Fraser, D., 2013. Attitudes of Canadian pig producers toward animal welfare http://dx.doi.org/10.1007/s10806-013-9477-4. (Ethics advance online publication). J Agric. Environ. http://dx.doi.org/10.1007/s10806-013-9477-4.(Ethicsadvanceonlinepublication).

Statistics Canada, 2006. Population, urban and rural, by province and territory. Available from: 〈http://www.statcan.gc.ca/tables-tableaux/sum-som/101/cst01/demo62a-eng.htm〉 (accessed 17.04.13.).

Taylor, N., Signal, T.D., 2005. Empathy and attitudes to animals. Anthrozoos 18, 18-27.

te Velde, H., Aarts, N., Van Woerkum, C., 2002. Dealing with ambivalence: farmers' and consumers' perceptions of animal welfare in livestock breeding. J. Agric. Environ. Ethics 15, 203-219.

Tuyttens, F.A.M., Vanhonacker, F., Langendries, K., Aluwe, M., Millet, S., Bekaert, K., Verbeke, W., 2011. Effect of information provisioning on attitude toward surgical castration of male piglets and alternative strategies for avoiding boar taint. Res. Vet. Sci. 91, 327-332. 
Tuyttens, F.A.M., Vanhonacker, F., Van Poucke, E., Verbeke, W., 2010. Quantitative verification of the correspondence between the Welfare Qualitys operational definition of farm animal welfare and the opinion of Flemish farmers, citizens and vegetarians. Livest. Sci. 131, 108-114.

Vanhonacker, F., Van Poucke, E., Tuyttens, F., Verbeke, W., 2010. Citizens' views on farm animal welfare and related information provision: exploratory insights from Flanders, Belgium. J Agric. Environ. Ethics 23, 551-569.

Vanhonacker, F., Verbeke, W., 2011. Consumer response to the possible use of a vaccine method to control boar taint v. physical piglet castration with an aesthesia: a quantitative study in four European countries. Animal 5, 1107-1118.

Vanhonacker, F., Verbeke, W., Tuyttens, F.A.M., 2009. Belgian consumers' attitude towards surgical castration and immunocastration of piglets. Anim. Welf. 18, 371-380.

Vanhonacker, F., Verbeke, W., Van Poucke, E., Tuyttens, F.A.M., 2008. Do citizens and farmers interpret the concept of farm animal welfare differently? Livest. Sci. 116, 126-136.

Veissier, I., Jensen, K.K., Botreau, R., Sandoe, P., 2011. Highlighting ethical decisions underlying the scoring of animal welfare in the Welfare Qualitys scheme. Anim. Welf. 20, 89-101.

Verhoog, H., Van Bueren, E.T.L., Matze, M., Baars, T., 2007. The value of 'naturalness' in organic agriculture. Njas Wagening. J. Life 54, 333-345.

Webster, A.J.F., 2009. The virtuous bicycle: a delivery vehicle for improved farm animal welfare. Anim. Welf. 18, 141-147. 